\title{
I. Die Ausgangslage: Kräfte, Tendenzen, Optionen
}

Dem großen Krieg, der vom Sommer 1914 bis zum Herbst 1918 Europa zutiefst erschüttert und sich durch das Eingreifen Japans, der Türkei und der Vereinigten Staaten von Amerika in der Tat zu einem Weltkrieg ausgeweitet hatte, war ein Zustand gefolgt, in dem die Zukunft der europäischen Staaten so unruhig und friedlos erschien wie nach keinem anderen militärischen Konflikt der vorhergegangenen zweihundertfünfzig Jahre. Das galt für die inneren Verhältnisse der Länder Europas wie auch - in wechselseitiger Abhängigkeit - für die Beziehungen zwischen den Staaten. Letzteres vor allem war - und das ist weniger paradox gewesen, als manche Beteiligte später meinten - gerade dem Willen der Sieger zu danken, dem europäischen Kontinent eine stabile Nachkriegsordnung zu geben.

Geschöpfe eines wissenschaftsgläubigen Zeitalters, hingen die Politiker und Diplomaten der Siegermächte, die in den ersten Nachkriegsjahren die Friedensverträge mit den Besiegten festzulegen hatten, der Vorstellung an, daß nicht nur in Staat und Gesellschaft, sondern auch im internationalen System zivilisierender und humanisierender Fortschritt machbar sei, sofern jetzt, beim Friedensschluß, nicht einfach der entstandenen Machtlage gefolgt, vielmehr ein vernünftiger und Gerechtigkeit schaffender Grundgedanke für eine auf Dauer Frieden stiftende Neukonstruktion der europäischen Staatengesellschaft gefunden werde; an der Notwendigkeit einer solchen Neukonstruktion schien nach viereinhalb Jahren eines ungewöhnlich blutigen Krieges kein Zweifel erlaubt zu sein1. Der für den Aufbau als tauglich angesehene Grundsatz war, nicht zuletzt unter dem Einfluß der 1917 in den Krieg eingetretenen USA, bereits vor Kriegsende entdeckt worden: das Selbstbestimmungsrecht der Völker. In den Augen angelsächsischer Friedensmacher kam dem Begriff durchaus der Charakter eines gesellschaftspolitischen Appells zu, eines Appells an die mittel-, ost- und südeuropäischen Nationen, liberaldemokratische Verfassungen - formal und real - zu

1 Hierzu Baumgart, Vom europäischen Konzert zum Völkerbund; Bosl (Hrsg.), Versailles St. Germain - Trianon; Goldstein, Winning the Peace; Gunzenhäuser, Pariser Friedenskonferenz 1919; Graml, Europa zwischen den Kriegen; Joll, Europe since 1870; Link (Hrsg.), Woodrow Wilson; Mayer, Politics and Diplomacy; Niedhart, Internationale Beziehungen 1917-1947; Schulz, Revolutionen und Friedensschlüsse. Jetzt auch Möller; Europa zwischen den Weltkriegen. 
schaffen, in erster Linie umschrieb er aber die Absicht, das Nationalstaatsprinzip durchzusetzen, auf dem europäischen Kontinent leidlich homogene, also saturierte und danach zur friedlichen Lösung internationaler Konflikte befähigte Nationalstaaten zu etablieren.

Hatten die Westmächte im Zeichen dieses Ordnungsprinzips schon während der Kriegsjahre nationale Befreiungsbewegungen in Europa - ebenso im Nahen Osten - politisch, militärisch und finanziell unterstützt, so verhalfen sie nun nach dem Krieg, auf der Pariser Friedenskonferenz, solchen Bewegungen tatsächlich zu eigener Staatlichkeit; existierende Nationalstaaten, die sich jedoch wie Rumänien und Serbien als unvollkommen verstanden, wurden entsprechend arrondiert. Dies hat zwei große Reiche und ein kleineres Reich völlig zerstört: das osmanische Imperium, das habsburgische Imperium und dazu noch das ungarische Imperium. Die Türkei büßte ihre beträchtlichen arabischen Besitzungen ein und sah sich auf das anatolische Kernland beschränkt, die Donaumonarchie zerfiel in etliche Nachfolgestaaten, und Ungarn verlor die Slowakei an die neugeschaffene tschechoslowakische Republik, das Burgenland an Deutsch-Österreich, KroatienSlawonien an Jugoslawien, die Bukowina, Siebenbürgen und Arad an Rumänien, das Banat an Rumänien und Jugoslawien. Zwei weitere Reiche mußten herbe Verluste hinnehmen: Rußland fand sich aller seiner Ostseeprovinzen beraubt, im Westen seiner polnischen Territorien und im Südosten Bessarabiens. Deutschland hatte Elsaß-Lothringen an Frankreich, Eupen-Malmedy an Belgien, Posen, Teile Westpreußens und Oberschlesiens an den jungen polnischen Staat, das Memelland an Litauen, einen Streifen in Schleswig an Dänemark und das Hultschiner Ländchen an die Tschechoslowakei abzutreten, außerdem Verzicht auf seine afrikanischen, fernöstlichen und pazifischen Kolonien zu leisten; Danzig fiel zwar nicht an Polen, wurde jedoch abgetrennt und als Freie Stadt unter Völkerbundsverwaltung gestellt. In den Auflösungs- beziehungsweise Schrumpfungsprozessen stürzten außerdem die bisher regierenden Dynastien, und sowohl die übriggebliebenen Kernländer wie die gestutzten Staaten verwandelten sich in Republiken; Ungarn freilich gerierte sich weiterhin als Monarchie - als eine Monarchie, die nur genötigt sei, für eine Weile ohne Monarch zu existieren².

Dieser Vorgang schnitt so tief, scharf und schmerzhaft in die gewachsene europäische Staatenwelt ein, daß bereits er, statt Frieden und Stabilität zu bescheren, nichts als Anlässe für künftigen Streit und Hader schuf, zumal naturgemäß gerade die politischen Eliten in Reststaaten wie Ungarn oder in verkleinerten Reichen wie Deutschland und Rußland weder willens noch fähig waren, auf das Denken in imperialen Kategorien und auf das Streben nach Rückgewinnung des Verlorenen, ob Länder, ob Geltung, ob Macht, zu verzichten. Zwar hatte in Rußland eine neue Elite aus kommunistischen Re- 
volutionären die alte Führungsschicht aus Aristokratie und einem noch kleinen Bürgertum weggefegt, aber die nun herrschenden Bolschewiki eigneten sich, ohne den Anspruch auf die globale sozialistische Revolution aufzugeben, bemerkenswert rasch die imperiale Denkweise ihrer Vorgänger an, die bald sogar Priorität erhielt. Träumten der Hochadel und die Gentry Ungarns von der Restauration des Reiches der Stephanskrone, so die roten Herren Moskaus von der Wiederherstellung der Grenzen des zaristischen Rußland; kaum ein paar Jährchen an der Macht, da schwor Marschall Klimmt J. Woroschilow, Volkskommissar für Verteidigung, einem deutschen Gesprächspartner, er und seine Genossen könnten sich niemals mit den derzeitigen Ostgrenzen Polens abfinden ${ }^{3}$.

Der hier angehäufte Zündstoff erhielt eine zusätzliche und seine besondere Brisanz, weil es den Pariser Friedensmachern nicht gelungen war, wenigstens jenes Prinzip, an dem sie die Neuordnung Europas zu orientieren verhießen und ja auch tatsächlich orientieren wollten, rein und überall anzuwenden. Wie denn auch; gerade in Ost- und Südosteuropa ließ das bunte Gemenge der Nationen und Nationalitäten homogene Nationalstaaten überhaupt nicht zu. Jedoch wirkten auf die Konstruktionsarbeit eben auch ein alter Fluch auf Friedenskonferenzen - prinzipienfremde Gesichtspunkte ein. So schien die wirtschaftliche und militärische Existenzsicherung der jungen und arrondierten Staaten - die außerdem zum Lager der Sieger zählten und überdies bei der Verteidigung der entstehenden Ordnung eine Rolle übernehmen sollten - gebieterisch zu verlangen, ihnen auch Territorien zuzuteilen, deren Bevölkerung keineswegs zur sogenannten „Staatsnation“ gehörte und durchaus gegen ihren Willen in einen ungeliebten oder sogar gehaßten Staat gezwungen wurde. In solchen Fällen blieb die Berufung auf das Selbstbestimmungsrecht ohne Echo. Die jeweilige ethnische Gruppe sah sich, statt den Anschluß an einen Staat ihrer Wahl und Nation wählen zu dürfen, plötzlich als „Minorität" in einem fremdnational bestimmten Staat und dort, da die neuen Staatsnationen - fast naturgemäß - einen rabiaten Nationalismus an den Tag legten und mitnichten dem Anspruch auf Einrichtung eines - ihres - Nationalstaats zu entsagen gedachten, permanenter Benachteiligung und zugleich permanentem Einschmelzungsdruck ausgesetzt. So lebten nun etwa in Rumänien mehr äußerst nationalbewußte Ungarn, in Polen mehr antipolnische Ukrainer, im jetzt Jugoslawien getauften Groß-Serbien mehr leidenschaftlich serbenfeindliche Kroaten, als verkraftbar sein konnten; die Tschechoslowakei beherbergte, von kleineren Minder-

3 Hinsichtlich Bessarabiens äußerten sich in gleichem Sinne z.B. Außenkommissar M. Litwinow am 28. 11. 1930 und der sowjetische Botschafter in Berlin, Leo Chintschuk, am 12. 12. 1931; Aufzeichnung Curtius bzw. Aufzeichnung Bülow jeweils an den genannten Tagen; PA, R 70502 bzw. R 29449. Die Äußerung Woroschilows am 14. 11.1931 in einer Unterhaltung mit General Wilhelm Adam, Aufzeichnung des deutschen Botschafters in Moskau, Herbert v. Dirksen, vom 14. 11. 1931; PA, R 29516. 
heiten abgesehen, nicht weniger als 3,5 Millionen höchst unwillige Staatsbürger deutscher Herkunft, die - alsbald Sudetendeutsche genannt - in dem liberaldemokratischen Staatswesen einerseits jede Freiheit hatten, ihr deutsches Nationalbewußtsein zu hegen, zu pflegen und zu schärfen, andererseits aber kaum eine Möglichkeit besaßen, die Außen- und Innenpolitik der Republik mitzubestimmen oder wenigstens zu beeinflussen ${ }^{4}$.

Deutschland war im Grunde am sanftesten behandelt worden. Die Abtretung Elsaß-Lothringens an Frankreich und Abtretungen an Polen waren wenngleich sich über die Gerechtigkeit der nach einer Volksabstimmung verfügten Teilung Oberschlesiens trefflich streiten ließ - keine Sünden gegen das Selbstbestimmungsrecht, sondern Folgen dieses Prinzips, da die Bewohner jener Regionen mehrheitlich im französischen beziehungsweise polnischen Staat zu existieren wünschten. Gewiß hatten die Sieger das Saarland aus dem Reichsverband gelöst und unter Völkerbundsverwaltung gestellt, jedoch nur für fünfzehn Jahre, und der Ausgang der dann vorgesehenen Volksabstimmung stand nie in Frage. Allerdings war nicht nur den Sudetendeutschen, sondern auch den Deutschen in Österreich der verlangte Anschluß an das Reich und damit die Wahrnehmung des Selbstbestimmungsrechts verwehrt worden; ihnen hatten die Friedensmacher eine eigene Staatlichkeit oktroyiert. Wäre den Österreichern, womöglich noch mit den Sudetendeutschen, das Selbstbestimmungsrecht zugestanden worden, hätten die Siegermächte das geschlagene Deutschland zum Hegemon Europas erhoben und damit das Kriegsergebnis ins Gegenteil verkehrt. Ein solches Verhalten zu erwarten oder zu fordern, hieß und heißt die menschliche Natur und das Wesen von Menschen gemachter Politik gründlich verkennen. Die Behandlung der österreichischen und sudetendeutschen Anschlußbewegung war durchaus verständlich, ebenso verständlich wie die Entschlossenheit, den jungen Staaten zur Lebensfähigkeit zu verhelfen. Auf der anderen Seite ist nicht weniger wahr: die Verständlichkeit, in manchen Fällen sogar Unabweisbarkeit der alliierten Politik änderte nichts daran, daß sie Herde künftiger Konflikte produzierte.

$\mathrm{Zu}$ den verletzten, verbitterten und nach Restauration trachtenden Imperialisten, die für das Selbstbestimmungsrecht der Völker nicht das geringste Verständnis, sondern nur Verachtung übrig hatten, gesellten sich also aus dem Kreis der Besiegten auch starke Gruppen, die deshalb zu den natürlichen Feinden der neuen europäischen Ordnung gehörten, weil ihnen das Selbstbestimmungsrecht vorenthalten worden war. In der Realität gab es freilich keine reinliche Scheidung. Individuen, politische Parteien und Organisationen, ethnische Gruppierungen konnten sehr wohl von beiden Gravamina gleichzeitig motiviert sein. Am deutlichsten war das bei den Sude-

4 Hoensch, Tschechoslowakei. Ferner zum Problem U. Corsini/D. Zaffi (Hrsg.), Minderheiten. 
tendeutschen, die unentwegt für sich das Selbstbestimmungsrecht einforderten und unter Berufung auf dieses Prinzip den tschechischen Machtanspruch mit aufrichtiger Empörung verdammten, daneben aber durchaus Bereitschaft zeigten, im Rahmen eines Großdeutschen Reiches Herrschaft über Tschechen auszuüben. Doch fand sich selbst im Kreise der Siegermächte ein Staat, der sich als konsequenter Gegner des entstandenen Status quo fühlte und verhielt. Italien hatte zwar keinen Quadratkilometer und keine Menschenseele verloren, im Gegenteil das Trentino, Triest, den größten Teil Istriens und überdies das deutschsprachige Südtirol bis zur Brennergrenze erhalten, doch glaubte eine Mehrheit der Italiener trotzdem das Recht auf tiefe Enttäuschung zu haben, da erheblich weiter reichende - und während des Krieges von den Verbündeten Italiens auch in Aussicht gestellte - Ansprüche, so auf Teile Dalmatiens und Albaniens, auf die Inseln des Dodekanes und auf zusätzliches Kolonialgebiet in Afrika, unerfüllt geblieben waren. Im Zorn über die entgangenen Gewinne sprachen viele Italiener bald vom "verstümmelten Frieden“ - ein Wort, das ebenso realitätsblind und gefährlich war wie die zur gleichen Zeit in Deutschland wuchernde "Dolchstoß-Legende“. In Wahrheit hatte sich der italienische Nationalismus schon vor dem Krieg zu einem Imperialismus gesteigert, der - von den parallelen Imperialismen der deutschen oder der habsburgischen oder der zaristischen Führungsschichten qualitativ kaum unterschieden ein Anrecht darauf zu haben meinte, sämtliche mediterrane, adriatische und ägäische Regionen italienischer Herrschaft zu unterwerfen, wobei zur mediterranen Region nicht allein praktisch ganz Nordafrika, sondern auch die französische Riviera gerechnet wurde. Daß ein solcher Imperialismus auf der Pariser Friedenskonferenz enttäuscht werden mußte, hat die Bitterkeit, von der die italienischen Nationalisten befallen wurden, nicht gemildert. Die im Oktober 1922 als Resultat innenpolitischer Konflikte an die Macht gelangten, von Benito Mussolini geführten Faschisten standen in dieser nationalistisch-imperialistischen Tradition, ja sie träumten noch begehrlicher vom Mittelmeer als dem „mare nostrum“, und so trat auch Italien unwiderruflich neben alle anderen Staaten, die ständig auf Gelegenheiten zur Korrektur der Kriegsergebnisse lauerten ${ }^{5}$.

Daß sich Europa somit spaltete, daß sich ein Klub konservativer Verteidiger oder doch Anhänger des Status quo, dessen Mitglieder vor allem Frankreich, Großbritannien, die Tschechoslowakei und Rumänien waren, in permanenter Konfrontation mit einer revolutionär gestimmten Partei von Feinden des Status quo befand, daß also die auf der Pariser Friedenskonferenz geschaffene europäische Ordnung ein recht zartes, ja zerbrechliches Gebilde war, stand jedem Europäer, der sich mit Politik befaßte, von Anfang an sehr deutlich vor Augen. Um so eifriger bemühten sich die Angehö- 
rigen des Klubs darum, die Angehörigen der Partei an der aktiven Verfolgung revisionistischer Politik zu hindern. In erster Linie galten solche Anstrengungen naturgemäß dem gefährlichsten, weil potentiell stärksten Revisionisten: Deutschland. Namentlich Frankreich, das durch die Oktoberrevolution in Rußland und durch die revisionistischen Neigungen auch der neuen Herren Moskaus seinen stärksten Bundesgenossen auf dem europäischen Kontinent verloren hatte, dem außerdem eine - als Ausgleich für den Pariser Verzicht auf das Vorschieben der Ostgrenze Frankreichs bis zum Rhein - zugesagte amerikanisch-britische Garantie der eigenen Sicherheit auf Grund des Rückfalls der Vereinigten Staaten in politischen Isolationismus schließlich doch entgangen war, namentlich Frankreich also unternahm alles, um den dräuenden östlichen Nachbarn in Fesseln zu schlagen.

Um einen Ersatz für das nicht mehr existierende russische Bündnis zu schaffen, zimmerten die Pariser Politiker ein Allianzsystem, als dessen östlicher Pfeiler Polen fungierte und das sich im Südosten auf die sogenannte „Kleine Entente“ stützte, zu der sich die Tschechoslowakei, Jugoslawien und Rumänien, die drei großen Gewinner der Pariser Friedenskonferenz, zusammengeschlossen hatten. Die Allianz sollte Deutschland in Schach halten, nicht zuletzt durch wachsame Kontrolle etwaiger österreichischer Anschlußtendenzen, und zugleich das ja ebenfalls unruhige Italien daran hindern, seinen imperialistischen Gelüsten nachzugeben, namentlich daran, Beutezüge auf dem Balkan zu unternehmen. Die vier Staaten übernahmen bereitwillig die ihnen von Paris zugedachte Rolle, schienen sie doch dadurch eine französische Garantie ihres Bestands gegen deutsche und italienische Anschläge zu erhalten, eine Garantie, ohne die sie ihre Lage für äußerst gefährdet ansehen mußten ${ }^{6}$.

Allerdings sah das Gebäude von Anfang an nicht sehr vertrauenerwekkend aus. Es bot gewiß Schutz gegen den italienischen und den ungarischen Revisionismus, jedoch konnte es den deutschen Revisionismus nur abhalten, solange Deutschland schwach war. Wie sollte es Bestand haben, wenn das Deutsche Reich die nach dem Kriege zunächst natürliche Erschöpfung überwand, seine außenpolitische Bewegungsfreiheit zurückgewann und dann womöglich nicht nur seine eigenen revisionistischen Ziele verfolgte, sondern sich an die Spitze der ganzen Revisionisten-Partei setzte? Mithin schien - so glaubten die ersten französischen Nachkriegskabinette - simple Logik zu gebieten, Deutschland möglichst lange in einem Zustand militärischer und außenpolitischer Ohnmacht zu halten. Im Friedensvertrag mit Deutschland, der am 28. Juni 1919 im Spiegelsaal des Schlosses von Versailles - wo 1871 die Gründung des Deutschen Reiches proklamiert worden war - unterzeichnet wurde, hatte sich Frankreich das Recht gesichert, die linksrheinischen deutschen Territorien zu besetzen und rechts des Rheins

6 Wandycz, France and her Eastern Allies; Adam, Richtung Selbstvernichtung. 
Stützpunkte zu unterhalten. Das Recht wurde wahrgenommen, und anfänglich beantwortete Frankreich größere oder kleinere oder auch nur sich abzeichnende deutsche Verstöße gegen den Versailler Vertrag mit der Okkupation weiterer deutscher Gebiete: so am 8. März 1921, als Frankreich auf die deutsche Ablehnung einer Reparationsforderung in Höhe von 226 Milliarden Mark mit der Besetzung Düsseldorfs, Duisburgs und Ruhrorts reagierte, so am 11. Januar 1923, als der vom Kabinett Cuno angekündigten Einstellung von Reparationszahlungen die Besetzung des Ruhrgebiets folgte. Auch suchten französische Politiker und Militärs die Okkupationen zur Ermutigung und Finanzierung separatistischer Gruppen an Rhein, Ruhr und in der Pfalz zu nutzen ${ }^{7}$. Ferner war Deutschland die Kraft zu offensivem und selbst defensivem militärischen Handeln genommen worden. Der Friedensvertrag begrenzte die Stärke des deutschen Heeres auf 100000 , die der Marine auf 15000 Mann, und er verbot die allgemeine Wehrpflicht ebenso wie Flugzeuge, Panzer, U-Boote und schwere Artillerie. Vor allem aber war Deutschland auf französisches Drängen mit einer ungeheuren und im Grunde unbezahlbaren Reparationsschuld belastet worden. Begründet wurde die Schuld mit Deutschlands Verantwortung für den Krieg und damit für alle Schäden, die den Alliierten durch den Krieg entstanden waren (Artikel 231 des Vertrags von Versailles, sogenannter „Kriegsschuldartikel") $^{8}$.

In der Tat galten die Reparationen als Strafe, und in der Tat dienten sie zur Finanzierung des Wiederaufbaus in Belgien, Frankreich, Italien, Jugoslawien und Rumänien. Ebenso dringend brauchten die Westmächte Geld, um die gewaltigen Kredite abzahlen zu können, die sie während des Krieges von den Vereinigten Staaten bekommen hatten; die USA bestanden lange Jahre unerbittlich auf Rückzahlung. Jedoch war in französischen Augen nicht weniger wichtig, daß die Reparationszahlungen Deutschlands wirtschaftliche und politische Erholung hemmten und insbesondere Deutschlands Fähigkeit, Geld für militärische Zwecke auszugeben und eine Revisionspolitik stützende Armee zu finanzieren, drastisch beschränkten; eine höchst probate Ergänzung der Entwaffnungsklauseln des Versailler Vertrags.

Gewiß hatten sich die Friedensmacher auch um positive Friedenssicherung bemüht, ebenso darum, den nun in fremde Nationalstaaten gezwungenen Minoritäten die Pille etwas zu versüßen. So war von den Siegern ein Völkerbund ins Leben gerufen worden, dessen Satzung Bestandteil des Versailler Vertrags war. Mit diesem Versuch, liberaldemokratischen Parlamentarismus auf die Staatengesellschaft zu übertragen, sollte ein System kollek-

7 Duroselle, Histoire diplomatique.

8 Bariéty, Conférence de la paix; Sharp, The Versailles Settlement; Dickmann, Die Kriegsschuldfrage. 
tiver Sicherheit errichtet werden, das zwar kriegerische Veränderungen des Status quo ausschloß, aber friedlichen Wandel ausdrücklich zuließ. Der Völkerbund, dessen Sitz Genf wurde, bestand zunächst aus 32 Siegerstaaten - plus 13 neutral gebliebene Länder -, doch war die Aufnahme der Besiegten durchaus vorgesehen, die dann begründbare revisionistische Forderungen zumindest in der Theorie friedlich im Rahmen des Bundes anstreben konnten. Außerdem schuf der Völkerbund ein kompliziertes Geflecht von Minderheitenschutzverträgen, dazu bestimmt, die "Staatsnationen“ zu zügeln und ihnen jedenfalls die staatsbürgerliche und wirtschaftliche Gleichberechtigung ihrer Minoritäten abzuringen?.

Indes fanden die Besiegten all das wenig überzeugend. Sie sahen, daß Artikel 19 der Satzung, der es der Vollversammlung erlaubte, Mitgliedern die Revision unanwendbar gewordener Verträge und friedensgefährdender internationaler Verhältnisse zu empfehlen, doch sehr zurückhaltend formuliert war, und sie sahen ferner, daß Artikel 10 jedes Mitglied verpflichtete, nicht nur die politische Unabhängigkeit, sondern auch die territoriale Integrität der anderen Bundesmitglieder zu respektieren und sogar zu schützen. Wie sollte da Revisionspolitik im Rahmen des Völkerbunds und friedlich gemacht werden? Auch gehörten die Sowjetunion und die USA dem Bund gar nicht an. Die sowjetischen Führer begriffen den Völkerbund als eine Vereinigung kapitalistischer Staaten und als Instrument der kapitalistischen Hauptmächte Großbritannien und Frankreich. In den Vereinigten Staaten wiederum war Präsident Woodrow Wilson, der zu den Vätern der neuen Institution zählte und sich von ihr aufrichtig eine fortschrittliche Revolutionierung der internationalen Beziehungen erhoffte, am Rückfall der Amerikaner in Isolationismus und am Widerstand seiner innenpolitischen Gegner gescheitert, die den demokratischen Politiker keinesfalls zu einer Art Weltpräsident aufsteigen lassen wollten. Das Fehlen der beiden potentiellen Weltmächte hatte aber zur Folge, daß im Völkerbund zunächst in der Tat Großbritannien, Frankreich und die französischen Trabanten in Ost- und Südosteuropa dominierten. Viele Angehörige der besiegten Völker verstanden daher den Bund noch nicht als eine Institution, in der sich eine Annäherung an ein Zeitalter allgemeinen Friedens manifestierte; für sie war er vorerst lediglich ein Werkzeug der Sieger zur Sicherung des allein in deren Interesse liegenden Status quo ${ }^{10}$.

Ein Jahrfünft lang standen die zwischenstaatlichen Beziehungen in Europa nahezu ausschließlich unter der Spannung zwischen den Verteidigern der neuen Ordnung und den potentiellen Revisionisten. Zwar konnten die Besiegten und Enttäuschten noch kaum etwas unternehmen, doch war stets

9 Dazu dic immer noch klassische Darstellung von Walters, League of Nations. Ferner Pfeil, Der Völkerbund.

10 Kimmich, Germany and the League of Nations. 
erkennbar, daß sie sehnsüchtig auf den Augenblick warteten, in dem zu praktischer Revisionspolitik übergegangen werden durfte, und daß sie sich so gut es ging auf diesen Augenblick vorbereiteten. So trat Italien in ein sehr enges Verhältnis zu Ungarn. Ungarische Politiker wie Gyula Gömbös nahmen schon Anfang der zwanziger Jahre Verbindung mit rechtsgerichteten Parteien und Organisationen in Deutschland auf, nicht zuletzt mit der in München beheimateten NSDAP Adolf Hitlers ${ }^{11}$. Auch in Italien beobachteten Mussolini und seine Faschisten mit größter Aufmerksamkeit die Vorgänge im Deutschen Reich; jedes Anzeichen von Erholung und von Kraftzuwachs wurde sorgfältig und freudig registriert, war doch aktive italienische Revisionspolitik ohne deutsche Hilfe nicht recht vorstellbar $^{12}$.

Und Deutschland selbst? Es war evident, daß die von hysterischen Zügen nicht freie und immer wieder zu rüden Methoden greifende Sicherheitspolitik Frankreichs, die einen ihrer Höhepunkte in der Ruhrbesetzung fand, den sozusagen naturgegebenen deutschen Revisionismus ebenfalls zu fiebriger Hitze trieb. Frankreich galt rasch nicht allein als ein „Erbfeind“, sondern als der „Erzfeind“ Deutschlands und der Deutschen. Georges Clemenceau, in der letzten Kriegsphase fast diktatorisch amtierender französischer Ministerpräsident und im Reich zur Symbolfigur französischer Deutschfeindlichkeit stilisiert, habe gesagt, so erzählte man sich allenthalben, es gebe „20 Millionen Deutsche zuviel auf der Welt“. Jahre später bat der Präsident des Reichsarchivs das Politische Archiv des Auswärtigen Amts um Verifizierung des Ausspruchs. Wie meist in solchen Fällen stellte sich heraus, daß Clemenceau nichts dergleichen gesagt hatte. Am 9. Juli 1930 mußte Victor v. Heeren (Abteilung II des A.A.) dem Reichsarchiv mitteilen: „Clemenceau selbst hat den Ausspruch in amtlicher oder nachprüfbarer Form nicht getan. " 13 Zuvor und auch danach glaubten nur allzu viele Deutsche an die Echtheit der Äußerung und meinten überdies, in der Formel Clemenceaus seien Grundmotiv und Leitprinzip französischer Deutschlandpolitik haargenau getroffen.

Eine der wichtigsten Folgen war die sehr schnell bündnisartige Form annehmende Verbindung zwischen Deutschland und der Sowjetunion ${ }^{14}$. Sie begann 1920 mit einer durchaus polenfeindlichen und für die Sowjetunion

11 Gömbös erinnerte Hitler daran, als er am 6.2. 1933 zur Ernennung zum Reichskanzler gratulierte; PA, R 74146. Vgl. auch Aufzeichnung Schlimper, 26. 8. 1931; PA, R 74142, und Aufzeichnung Mackensen, 19. 6. 1934; PA, R 74142.

12 Lowe/Marzari, Italian Foreign Policy, S. 183 ff.; Woller, Rom, S. $141 \mathrm{ff}$.

13 PA, R 70502.

14 Schieder, Rapallo-Vertrag; Helbig, Träger der Rapallo-Politik; Wengst, Graf BrockdorffRantzau; Graml, Rapallo-Politik; Hildebrand, Das Deutsche Reich und die Sowjetunion; Rosenfeld, Sowjetrußland und Deutschland 1917-1922; ders., Sowjetunion und Deutschland 1922-1933. In die langfristige Darstellung deutscher Außenpolitik eingebettet Hildebrand, Das vergangene Reich, S. $838 \mathrm{ff}$. 
auch praktisch nützlichen Neutralität Deutschlands im polnisch-sowjetischen Krieg. Sie gewann feste Gestalt 1921/22, als Reichswehr und Rote Armee eine für beide Seiten profitable Zusammenarbeit aufnahmen und diese Kooperation - dazu ein gewisser Wirtschaftsaustausch - mit dem am 16. April 1922 geschlossenen Vertrag von Rapallo auch einen diplomatischpolitischen Rahmen erhielt. Grundlage der Beziehung war, allgemein gesprochen, die generell antiwestliche Orientierung der Partner und die Hoffnung, durch gegenseitige Stützung die jeweils eigene Stellung gegenüber den als Feinde gesehenen Westmächten zu stärken. Die sowjetische Führung versprach sich, wenn sie dazu beitrug, Deutschland auf antiwestlichem Kurs zu halten, insbesondere auch die Verhinderung einer antisowjetischen Einheitsfront der kapitalistischen Staaten, wie sie sich im Frühjahr 1922 in der Tat als Möglichkeit abgezeichnet hatte. In deutschen Augen spielte die militärische Konnexion eine wichtige Rolle, die es erlaubte, die Entwaffnungsbestimmungen des Versailler Vertrags wenigstens in bescheidenem Maßstab zu umgehen. Vor allem aber begriffen beide Partner die Allianz als notwendige Voraussetzung und als Vorspiel gemeinsamer Revisionspolitik gegen Polen. Und so mächtig wirkten antiwestliche und antipolnische Emotionen oder, anders gesagt, die nach solchen Emotionen definierten Interessen, daß die Moskauer Bolschewiki überhaupt keinen Anstand nahmen, sich mit konservativen preußisch-deutschen Offizieren und mit Repräsentanten des nationalen deutschen Bürgertums zu verbrüdern, und daß auf der anderen Seite preußische Aristokraten und bürgerliche deutsche Politiker - wie auch Vertreter des Kapitals - nicht die geringsten Bedenken trugen, mit roten Revolutionären zu konspirieren, und dabei in Deutschland allenfalls links von der Mitte auf Opposition stießen.

Angesichts der tiefen Spaltung Europas und angesichts der bitteren Konflikte, die bei dieser Spaltung schon in naher Zukunft erwartet werden mußten, grenzte es an ein Wunder, daß die Beziehungen zwischen den europäischen Staaten in den Anfangsmonaten des Jahres 1930 erstmals seit dem Kriege nicht mehr zu weiterer Verschlechterung zu tendieren, ja sogar Verbesserung zu verheißen schienen. In den Mächten, die an der Erhaltung des Status quo interessiert waren, begann sich gedämpfter Optimismus zu regen. Konnte die Partei der Feinde des Status quo vielleicht doch mit der Versailler Ordnung versöhnt werden? Genauer gefragt: Konnte der potentiell stärkste Revisionist, Deutschland, vielleicht doch dazu gebracht werden, eine friedlich-stabile Gegenwart und Zukunft den Fährnissen aktiver Revisionspolitik vorzuziehen, und konnten danach all die anderen Revisionisten, denen ohne deutsche Führung und Hilfe die Kraft zum revolutionären Umsturz der Staatengesellschaft fehlte, zu Tolerierung und allmählicher Gewöhnung genötigt sein?

Der Grund solcher Fragen und der Grund dafür, daß eine bejahende Antwort immerhin denkbar wurde, war eine deutsch-französische Annäherung, 
die 1924 eingesetzt und sich trotz größerer und kleinerer - von beiden Seiten verschuldeter - Zwistigkeiten bis zur Jahreswende 1929/30 kontinuierlich fortgesetzt hatte ${ }^{15}$. Es gab sowohl in Frankreich wie in Deutschland etliche Politiker, Diplomaten und Intellektuelle, die an die Verständigung ihrer Länder glaubten und daher konsequent daran arbeiteten, aus Annäherung tatsächlich Verständigung zu machen. Gelungen war das bis Anfang 1930 noch nicht. Den Beginn des Prozesses hatte ja auch nicht französische und deutsche Verständigungsbereitschaft bewirkt, sondern schiere Erschöpfung. In Deutschland hatten sich alle politischen Gruppierungen, von der extremen Linken und der extremen Rechten abgesehen, im Spätsommer 1923 eingestehen müssen, daß das Deutsche Reich als Resultat einer Politik des permanenten Konflikts mit Frankreich in ein nicht mehr auszuhaltendes finanzielles und innenpolitisches Chaos gestürzt worden war. Zuletzt hatte die Finanzierung des passiven Widerstands gegen die Besetzung des Ruhrgebiets, da das benötigte Geld vornehmlich von der Notenpresse produziert worden war, die ohnehin grassierende Inflation zu einer irrwitzigen Hyper-Inflation gesteigert, die ganze Gesellschaftsschichten ruinierte und in der revolutionäre Bewegungen jeder Art prächtig gediehen. Gustav Stresemann, vom 13. August bis zum 30. November 1923 Reichskanzler einer Koalitionsregierung und in allen folgenden Kabinetten bis zu seinem Tode am 3. Oktober 1929 Außenminister, zog die Konsequenzen. Zwar war er damals noch kein Verständigungspolitiker im strengen Sinne des Worts, schon gar nicht ein europäisch denkender Staatsmann, wohl aber hatte sich der Annexionist der Kriegsjahre zu einem realistischen Patrioten entwickelt, der Deutschland im europäischen Zusammenhang sah. So begriff er, daß das Deutsche Reich nicht länger versuchen durfte, das Kriegsergebnis einfach zu ignorieren. Am 26. September 1923 brach er den passiven Widerstand an Rhein und Ruhr ab, und in den letzten Monaten des Jahres machte das Kabinett Stresemann mit der Schaffung der Rentenmark und dem Ausgleich des Haushalts auch der Inflation ein Ende. Der Abbruch des passiven Widerstands kam einer deutschen Kapitulation in der Reparationsfrage gleich, und die Stabilisierung der Währung erlaubte nun zum ersten Mal seit dem Kriege eine halbwegs brauchbare Berechnung der deutschen Zahlungsfähigkeit.

Daß Frankreich die deutsche Kapitulation annahm, lag in erster Linie daran, daß sich in Paris ebenfalls Realismus durchsetzte. Auch die Mehrheit der französischen Politiker sah ein ${ }^{16}$, daß eine Politik der Feindseligkeit und der simplen Niederhaltung Deutschlands das Sicherheitsproblem lediglich für kurze Zeit zu lösen vermochte, das Problem im Grunde nur in die Zu-

15 Hierzu grundlegend und bis heute gültig Krüger, Die Außenpolitik von Weimar, S. 207 ff. Zu Stresemann vor allem Koszyk, Gustav Stresemann; ferner Hirsch, Stresemann; Turner, Stresemann. Republikaner aus Vernunft; Maxelon, Stresemann und Frankreich.

16 Hierzu Kaelble, Nachbarn am Rhein; V. Pitts, France and the German Problem; Hagspiel, Verständigung. 
kunft verlagerte, auf der anderen Seite aber für eine ständige Beunruhigung der europäischen Verhältnisse - vom Chaos in Deutschland ganz zu schweigen - sorgte und daher die bisherigen Bundesgenossen von Frankreich zu trennen drohte. Vor allem Großbritannien. In London dominierte längst wieder das Interesse - wirtschaftlich und auch sozusagen empirepolitisch begründet - an stabilen Zuständen auf dem europäischen Kontinent, und so redeten Premierminister, Foreign Office und britische Diplomaten nicht nur den Deutschen gut zu, zunächst in der Reparationsfrage endlich vor Frankreich zu kapitulieren, sondern sie setzten zugleich ihre französischen Freunde unter massiven Druck, die deutsche Kapitulation, wenn sie denn kommen sollte und als sie dann in der Tat kam, in versöhnlichem Geiste auch zu akzeptieren. Es gelang ihnen sogar, Frankreich gleichfalls zu einer Art Kapitulation zu bewegen: zwar nicht zum Verzicht auf deutsche Reparationen, wohl aber zum Verzicht auf die bislang ungehemmt praktizierte politische Instrumentalisierung des Reparationsanspruchs und auf die Unterstützung separatistischer Gruppen im Rheinland und in der Pfalz. So wurde in Paris eine auf rücksichtslose und totale Anwendung von Versailles pochende Politik der Vertragslogik von einer Politik der Vernunft abgelöst. Jedenfalls in Ansätzen.

Am 30. August 1924 konnte in London zwischen den Alliierten und dem Deutschen Reich eine Vereinbarung unterzeichnet werden, in der Deutschland einwilligte, wieder in fixen Jahresraten Reparationen zu zahlen, und sich außerdem dazu verstand, sein Finanzwesen partiell internationaler Kontrolle zu unterwerfen, bis zu einem gewissen Grade auch die Reichsbank, die überdies unabhängig von der Reichsregierung wurde. Dafür handelte sich Deutschland schon einen reparationspolitischen Vorteil ein. Künftig war die Reichsregierung nur noch für die Aufbringung der Jahresraten zuständig, während für den Transfer der Gelder in die Gläubigerstaaten das internationale Kontrollorgan verantwortlich zeichnete, das dabei darauf zu achten hatte, daß die Reparationszahlungen nicht zu einer Gefahr für die deutsche Währung wurden, das hieß nicht eine neue Inflation bewirkten. Vor allem aber tauschte Deutschland gegen seine reparationspolitische Kapitulation und gegen die Eingriffe in seine Souveränität eine internationale Garantie der Reichseinheit ein, unter der auch die französische Unterschrift stand. Ein Erfolg, den noch ein Jahr zuvor niemand in Deutschland für möglich gehalten hätte. Daß hinter der britischen Intervention auch bereits amerikanischer Einfluß - namentlich auf Frankreich - am Werke gewesen war, ließ sich daran erkennen, daß zu den Architekten des Reparationsplans ein Amerikaner gehört hatte, der nun dem fertigen Vertrag seinen Namen gab: General Charles G. Dawes, exzellenter Finanzmann und Administrator, im Weltkrieg hervorragender Logistiker in der amerikanischen Armee; kurz nach der Londoner Konferenz wurde er Vizepräsident der USA unter Präsident Calvin Coolidge. 
Mit der Annahme des Dawes-Plans war Deutschland wieder kreditwürdig geworden, und von einer internationalen Sofortanleihe abgesehen, die 800 Millionen Goldmark betrug und dem Reich den Start der Reparationszahlungen ermöglichen sollte, begannen amerikanische, britische und in bescheidenerem Maße sogar französische Kapitalgeber ihr Geld sogleich in Deutschland anzulegen ${ }^{17}$. Dieser Kreditstrom, der auch in den folgenden Jahren reichlich floß, diente nur zum geringeren Teil zur Finanzierung der Reparationsleistung. Überwiegend wurde in Wirtschaftsunternehmen investiert, gingen Anleihen an Länder und nicht zuletzt an Kommunen. Die deutsche Wirtschaft kam in Fahrt, der innere Markt kräftigte sich, der Lebensstandard breiter Schichten, gerade auch der Arbeiter, stieg, und danach konnte auch die Beruhigung der innenpolitischen Verhältnisse, wie sie mit der Währungsreform von 1923/24 verbunden war, zu Stabilisierung fortschreiten.

Der konjunkturelle Aufschwung war - ebenso wie die politische Erholung - keineswegs eine „Scheinblüte“, wie oft gesagt wurde und wird. Die Blüte war durchaus real, jedoch konnte sie, wie schon viele Zeitgenossen nicht verkannten, ungewöhnlich leicht ungewöhnlich großen Gefährdungen zum Opfer fallen. Viele Anleihen kamen als kurzfristige Kredite, wurden aber von den Empfängern, namentlich von den Kommunen, oft in Vorhaben gesteckt, die ihrer Natur nach langfristige Kredite erfordert hätten. Solange es keine Schwierigkeiten machte, abgelaufene und abgerufene Kredite durch neues kurzfristiges Geld zu ersetzen, funktionierte das System, wurde aber der Kreislauf gestört oder zum Stocken gebracht, führte eine wirtschaftliche oder politische Krise - womöglich beides - zur Desertion kurzfristiger Kredite, ohne daß Ersatz zu beschaffen war, brachen sogleich Katastrophen herein.

Zunächst war jedoch die wohltätige Wirkung, in Wirtschaft wie Politik, $\mathrm{zu}$ sehen und $\mathrm{zu}$ spüren, und in dem solchermaßen veränderten Klima konnten weitere Schritte folgen. Stresemann betrachtete den Dawes-Plan, wie auch die meisten Politiker in den alliierten Staaten, lediglich als Provisorium. Im fünften Jahr der Laufzeit des Plans sollte von den moderateren Raten der ersten vier Jahre wieder zu den weit höheren Raten der Vor-DawesPeriode zurückgekehrt werden. Für Stresemann hieß das nur, daß nach Ablauf der vier Jahre Verhandlungen aufgenommen werden müßten, und zwar nicht etwa über das Ausmaß einer Erhöhung, sondern über eine neuerliche Herabsetzung. Ebenso wichtig war in seinen Augen die Aufhebung der Finanzkontrollen und - da der Dawes-Plan bloß die Räumung des Ruhrgebiets und etlicher Städte des Rheinlands binnen eines Jahres zusagte - der Abzug französischer Truppen aus den laut Versailler Vertrag noch länger

17 Aldcroft, Die zwanziger Jahre; Kindleberger, A Financial History; Rowland (Hrsg.), Balance of Power. 
besetzten deutschen Territorien; außerdem hatte auch die für die Reichswehr höchst unbequeme Interalliierte Militärkontrollkommision zu verschwinden.

Nun war aber klar, daß man all dies allein dann zu erreichen hoffen durfte, wenn es gelang, Frankreich zur Zustimmung zu bewegen. Stresemann wußte sehr genau, daß Großbritannien bereit war - um der Stabilisierung Kontinentaleuropas willen -, gegenüber Deutschland AppeasementPolitik zu betreiben. Andererseits hatte er frühzeitig erkannt, daß die britische Neigung zum Appeasement nicht so weit ging, sich gegen Frankreich ausspielen zu lassen oder ein gegen Frankreich gerichtetes Bündnis mit Deutschland einzugehen. Die britische Regierung hatte 1923/24 bewiesen, daß sie durchaus fähig war, den französischen Freunden bei Verirrungen, das hieß bei allzu unruhestiftender Handhabung des Versailler Vertrags, in den Arm zu fallen und dabei auch ernstere Konflikte nicht zu scheuen. Doch Deutschland bei der allmählichen Lockerung von Versailler Bindungen behilflich zu sein, war den britischen Politikern nur möglich, wenn sich die deutsche Regierung in Paris um das französische Einverständnis mit den einzelnen Etappen bemühte und dabei selber Konzessionen machte. Frankreich war nicht zu umgehen; die partielle Abkehr von Versailles bedingte eine partielle deutsche Anerkennung von Versailles ${ }^{18}$.

Angesichts der gegenüber Versailles und Frankreich so feindlichen Stimmung großer Teile der deutschen Bevölkerung war die Wendung zu Realismus und Vernunft nicht nur ein innenpolitisch schwieriger, sondern sogar ein für Stresemann persönlich gefährlicher Akt; schließlich lag die Ermordung Matthias Erzbergers und Walther Rathenaus erst wenige Jahre zurück. Gleichwohl übermittelte Stresemann, von Lord D'Abernon, dem britischen Botschafter in Berlin, nachdrücklich ermuntert, der Regierung Großbritanniens am 20. Januar 1925 eine Note, in der er die freiwillige Anerkennung der deutschen Westgrenze anbot und einen die Anerkennung dokumentierenden wie garantierenden Sicherheitspakt der interessierten Mächte vorschlug. Die britische Regierung betrachtete das Dokument nicht ohne Skepsis. Die Skepsis galt jedoch nicht dem Vorschlag Stresemanns, sondern der deutschen Aufrichtigkeit und nicht weniger der Bereitschaft Frankreichs, sich auf das deutsche Projekt einzulassen. Auch durfte in Paris nicht der Verdacht auf eine deutsch-britische Konspiration geweckt werden. So vergingen einige Tage, ehe das britische Kabinett Ende Januar zu verstehen gab, $\mathrm{daß}$ die deutsche Note nicht ungünstig aufgenommen worden sei, und mit dem Hinweis, in derartigen Fragen könne England nicht ohne seine Alliierten verhandeln, einen ähnlichen deutschen Schritt in Paris empfahl. Stresemann folgte dem Wink und unterbreitete seine Vorschläge am 9. Februar

$18 \mathrm{Graml}$, Europa zwischen den Kriegen, S. $175 \mathrm{ff}$. 
1925 auch der französischen Regierung. Damit hatte er den Versuch zu einer deutsch-französischen Annäherung offiziell eröffnet ${ }^{19}$.

In Paris ließ man sich mit der Antwort freilich Zeit. Hier begegneten die deutschen Absichten noch viel größerem Mißtrauen als in London, und nachdem in die ohnehin schon längere Phase französischer Unschlüssigkeit am 26. April die Wahl des Generalfeldmarschalls Paul v. Hindenburg zum Reichspräsidenten gefallen war, eines allem Anschein nach typischen Repräsentanten des wilhelminischen Deutschland, erhielt das Mißtrauen neue Nahrung, zumal jeder Politiker und Journalist in Europa wußte, daß Hindenburg die Kandidatur nicht zuletzt auf Zureden des Großadmirals Alfred v. Tirpitz akzeptiert hatte, der allenthalben geradezu als klassische Symbolfigur für deutschen Militarismus und Imperialismus galt ${ }^{20}$. Indes wurde dann doch deutlich, daß die Wahl Hindenburgs keinen negativen Einfluß auf Stresemanns Kurs hatte. Langsam bekehrte sich die französische Regierung - wiederum nicht ohne lenkende und steuernde britische Pression - zu der Auffassung, daß es wohl besser sei, den Deutschen, statt sie sich vom Leibe zu halten, entgegenzukommen. Vielleicht gelang es einer Politik der Aussöhnung und Annäherung, Deutschland an den Status quo zu fesseln. Wie stark dieses Motiv - als Hoffnung - war, kam in der französischen Note deutlich zum Ausdruck, die am 16. Juni 1925 in Berlin einging. In ihr stimmte die französische Regierung Verhandlungen über die deutschen Vorschläge grundsätzlich $\mathrm{zu}$, wobei bezeichnenderweise bereits eine östliche Ergänzung des Garantiesystems angeregt - nicht verlangt - wurde. Ebenso bezeichnend war, daß die französische Regierung Deutschlands Eintritt in den Völkerbund, also die formelle Rückkehr des Reiches in die Staatengesellschaft, nicht etwa als Belohnung für deutsche Konzessionen in Aussicht stellte, sondern eine conditio sine qua non für erfolgreiche Verhandlungen nannte; sie sah darin einen dicken Faden, um Deutschland zu binden.

So begann eine Verhandlungsrunde, in der sich Deutsche und Franzosen allem Argwohn zum Trotz in der Tat näherkamen. Bedenkt man die Vorbehalte, namentlich die französischen Vorbehalte, so wurde bemerkenswert wenig Zeit gebraucht, bis Repräsentanten der Mächte zur Konferenz von Locarno zusammentreten und dann ebenso bemerkenswert zügig, vom 5 . bis 16 . Oktober 1925, konkrete Resultate aushandeln konnten ${ }^{21}$. Zwischen Deutschland, Großbritannien, Frankreich, Belgien und Italien wurde ein Garantiepakt vereinbart, der Deutschland zur Anerkennung der in Versailles gezogenen deutsch-französischen beziehungsweise deutsch-belgischen Grenze und zu der im Versailler Vertrag (Artikel 42 und 43) festgeleg-

19 Krüger, Die Außenpolitik von Weimar, S. 272.

20 Dorpalen, Hindenburg in der Geschichte der Weimarer Republik, S. 76.

21 Krüger, Die Außenpolitik von Weimar, S. $295 \mathrm{ff}$. 
ten Entmilitarisierung des Rheinlands verpflichtete. Deutschland und Belgien beziehungsweise Deutschland und Frankreich sagten sich $\mathrm{zu}$, „in keinem Falle zu einem Angriff oder zu einem Einfall oder zu einem Kriege gegeneinander zu schreiten“. Waffengewalt blieb nur zur Selbstverteidigung, das hieß zum Widerstand gegen eine Verletzung des Garantiepakts und im Rahmen einer vom Völkerbund beschlossenen Aktion erlaubt. Mithin war die Rückkehr Frankreichs zu der zwischen 1919 und 1924 verfolgten Politik bis zur Unmöglichkeit erschwert, zumal Deutschland mit Belgien und Frankreich noch Abkommen traf, die eine schiedsgerichtliche Regelung aller auftauchenden und nicht auf diplomatischem Wege lösbaren Streitfragen obligatorisch machten.

Daß die Abmachungen von Locarno in solchem Tempo zustande kamen, war nicht zuletzt einem persönlichen Element zu verdanken. Leiter des Foreign Office war in jenen Jahren Sir Austen Chamberlain, ein konservativer Politiker, der großen Respekt vor Deutschland - er hatte 1887 als junger Mann noch am Tische Bismarcks gesessen ${ }^{22}$ - mit tiefer Bewunderung französischen Geistes und französischer Kultur verband, sowohl in Berlin wie erst recht in Paris Vertrauen genoß und daher für die Rolle des britischen Vermittlers deutsch-französischer Annäherung die besten Voraussetzungen mitbrachte. Sein und Stresemanns Partner auf französischer Seite war Aristide Briand, der sich, ursprünglich Sozialist, zu einer der großen Gestalten der humanistischen Traditionen Frankreichs und des französischen Liberalismus entwickelt hatte ${ }^{23}$. Kein Pazifist, war er jedoch spätestens durch die Erfahrung des Weltkriegs zum Anhänger einer Politik der Kriegsverhütung um fast jeden Preis geworden; mithin lag ihm eine friedenssichernde Verständigung zwischen Frankreich und Deutschland wirklich am Herzen. $\mathrm{Daß}$ er prinzipienfest war, hinderte ihn nicht daran, taktisch geschickt $\mathrm{zu}$ operieren, und so durfte er auf eine glanzvolle politische Karriere zurückblicken. Vielen französischen Kabinetten hatte er angehört, oft als Regierungschef, und zur Zeit von Locarno amtierte er als Außenminister unter dem Ministerpräsidenten Paul Painlevé. Am 1. Dezember 1925 wurden die im Oktober formulierten Verträge in London unterzeichnet.

Ein Ziel war von Stresemann nicht erreicht worden. Obwohl er seine nicht geringe Überredungskunst aufgeboten und auch das zu Briand allmählich entstehende Vertrauensverhältnis zu nutzen versucht hatte, war es ihm nicht gelungen, die Westmächte für eine Abmachung zu gewinnen, in der sich Frankreich und Großbritannien gewissermaßen als Belohnung für den deutschen Verzicht auf Elsaß-Lothringen zur vorzeitigen Räumung der gemäß dem Friedensvertrag besetzten rheinischen Gebiete verpflichtet hätten. Schließlich mußte sich Stresemann mit dem Versprechen Briands be-

22 Chamberlain, Erinnerungen, S. $82 \mathrm{ff}$.

23 Siebert, Aristide Briand; Baumont, Aristide Briand. 
scheiden, daß er sich bemühen werde, die Räumung, die nicht als französische Konzession mit dem Locarno-Pakt verbunden werden könne, nach seiner Rückkehr in Paris als freiwillige Geste Frankreichs durchzusetzen. Was die Kölner Zone betraf, so vermochte Briand sein Wort zu halten. In den ersten Novembertagen, noch ehe die Verträge von Locarno in London unterzeichnet wurden, teilte er Stresemann mit, daß der Abzug der Truppen demnächst eingeleitet und bis Februar 1926 abgeschlossen sein werde. Er hatte sein Versprechen guten Glaubens gegeben, jedoch angesichts der noch immer breiten Front französischer Sekuritätsfanatiker vorerst nicht weiter gehen können. Erst im August 1929, wenige Monate vor seinem Tode, erhielt Stresemann die Zusage, daß auch in den beiden letzten Zonen die Okkupation im Laufe des Jahres 1930, bis zum 30. Juni, vorzeitig beendet werde.

Obwohl sich also nicht alle Wünsche erfüllt hatten, durften Briand und Stresemann dennoch annehmen, einen großen Erfolg für ihre Länder errungen zu haben. Deutschland hatte an Sicherheit, finanzpolitischer Stabilität und internationaler Bewegungsfreiheit gewonnen, zumal sich Großbritannien und Italien verpflichtet hatten, als Garantiemächte der Vereinbarungen von Locarno zu fungieren, das hieß bei einer deutschen Vertragsverletzung Frankreich und Belgien, bei einer französischen oder belgischen Vertragsverletzung Deutschland Beistand zu leisten. In Frankreich wiederum konnte man sich in dem Glauben wiegen, den unruhigen Nachbarn mit britischer Hilfe auf den Anfang eines Weges geschoben zu haben, der von Revanche und Revisionismus wegführte. In Deutschland wie in Frankreich schien die Phalanx der Gegner von Locarno zurückgedrängt werden zu können. Im übrigen Europa - und in den USA - hatten fast alle, die als Akteure oder Beobachter mit der internationalen Situation befaßt waren, erst recht den Eindruck, daß sich das deutsch-französische Verhältnis positiv entwickle, die noch überwiegend vom Krieg bestimmte Periode ihr Ende gefunden habe und das Tor zu einer friedlichen Zukunft des Kontinents aufgestoßen worden sei. Es war Ausdruck dieser kurz zuvor noch unvorstellbaren Zuversicht, daß Chamberlain und Dawes 1925, Briand und Stresemann 1926 den Friedensnobelpreis erhielten. Am 8. September 1926 wurde Deutschland in den Völkerbund aufgenommen, und zwar sofort als ständiges Ratsmitglied. Das stärkte die Zuversicht noch, brachte dem Deutschen Reich einen beträchtlichen Prestigegewinn, und als am 31. Januar 1927 die Interalliierte Militärkontrollkommission ihre Tätigkeit einstellte, wurde auch das als Signal verstanden, daß die Zeit vorbei sei, in der Deutschland mit einer Front von „Alliierten“ konfrontiert war, daß vielmehr Deutschland wieder als moralisch und politisch gleichrangiges und gleichberechtigtes Mitglied zum Kreis der europäischen Großmächte gehöre.

Im Lauf der nächsten Jahre sah sich das Deutsche Reich sogar bereits umworben, und zwar von ganz unterschiedlichen Freiern. Daß revisionistische Staaten wie Ungarn und Italien sehr aufmerksam den Zuwachs Deutsch- 
lands an Einfluß und realer politischer Kraft im internationalen Mächtespiel registrierten, war angesichts ihrer eigenen Ambitionen nicht weiter verwunderlich. Ihre Hoffnung auf deutsches Geleit nahm noch zu, als sich im Herbst 1929 die Räumung der letzten besetzten Zonen in Deutschland abzeichnete; danach mußten sich dem Reich größere Möglichkeiten für aktive Revisionspolitik öffnen ${ }^{24}$. Das Datum 30. Juni 1930 begann in ungarischen und italienischen Köpfen herumzuspuken. Ungarische Politiker, so Ministerpräsident Graf Bethlen am 26. Mai 1929 in einer Ansprache zur Enthüllung eines Gedenksteins für den „Unbekannten Ungarischen Soldaten“, akzentuierten Ungarns revisionistische Forderungen in bislang nicht gekannter Schärfe, und zwar nach Rücksprache mit dem deutschen Gesandten in Budapest, Hans v. Schoen ${ }^{25}$. Und hatte Graf Kuno Klebelsberg, der ungarische Kultusminister, noch im April $1929 \mathrm{zu}$ Stresemann gesagt, man wisse natürlich in Ungarn, „daß Deutschland vorerst eine gewisse Zurückhaltung bewahren" müsse ${ }^{26}$, so meinte Baron Kalman Kanya, Ungarns Gesandter in Berlin, als er ein Jahr später mit Staatssekretär Carl v. Schubert sprach, nach der Rheinlandräumung werde Deutschland doch die Hände freier haben und eine aktivere allgemeine Politik treiben können ${ }^{27}$.

Ähnliche Erwartungen regten sich in Italien und gingen auch dort wenngleich dies nicht allein von der deutschen Entwicklung verursacht war - mit lauten öffentlichen Bekundungen des italienischen Revisionismus, sogar mit unverhohlenen Kriegsdrohungen einher. Am 11. Mai 1930 hielt Mussolini in Livorno - "wenige Seemeilen von Korsika entfernt", wie der deutsche Botschafter in Rom beziehungsvoll anmerkte ${ }^{28}$ - eine Rede, in der er - so auch am folgenden Tag in Florenz - die „Opferbereitschaft des italienischen Volkes" beschwor, wenn es darum gehe, "sich aus der Gefangenschaft innerhalb des Meeres zu befreien, das einst in seiner Gesamtheit Rom untertan gewesen" sei. Rückblickend schrieb ein erfahrener deutscher Diplomat, Mussolini, der bereits während der Ruhrbesetzung Sympathien für Deutschland gezeigt und wohl schon bei der Beobachtung des nationalsozialistischen Putschversuchs vom November 1923 erstmals an eine spätere militärische deutsche Unterstützung italienischer Revisionspolitik gedacht habe, sei seit Mitte der zwanziger Jahre an einer Verständigung mit dem Deutschen Reich interessiert gewesen ${ }^{29}$. Zwar war der Duce Realist genug, um sich mit Stresemanns Locarno-Politik und mit Locarno selbst abzufinden, zumal die Italien zugefallene Rolle des zweiten Garanten der Vereinba-

24 Aufzeichnung Schubert über Gespräch mit Baron Kalman v. Kanya, ungarischer Gesandter in Berlin, 27. 5. 1930; PA, R 74146.

25 Schoen an AA, 27. 5. 1929; PA, R 74142.

26 Aufzeichnung Auswärtiges Amt, 25. 4. 1929; PA, R 74142.

27 Aufzeichnung Schubert, 27. 5. 1930; PA, R 74142. Staatssekretär Carl v. Schubert reagierte sehr zurückhaltend.

28 Neurath an AA, 19. 5. 1930; PA, R 70024.

29 Prittwitz, Ein Diplomatenleben, S. 153. 
rung seinen Großmachtgelüsten schmeichelte. Doch gegen Ende der zwanziger Jahre mehrten sich die Anzeichen dafür, daß Mussolini glaubte, Deutschland werde bald wieder genügend Handlungsfreiheit erlangt haben, und daß er sich rüstete, dann auf ein gutes und mit revisionspolitischen Spitzen versehenes Einvernehmen zwischen Berlin und Rom hinzuarbeiten.

Aber auch in Frankreich fand die Ansicht, man müsse sich mit Deutschland arrangieren, ja enger verbinden, immer mehr Anhänger. Das war einerseits durchaus eine Wirkung der Annäherungspolitik, wie sie Briand und Stresemann verfolgten, andererseits aber vornehmlich eine natürliche Reaktion auf die beunruhigende italienische Haltung. Schließlich waren da nicht allein die imperialistischen und antifranzösischen Brandreden des Duce. Italien leistete sich eine Militär- und Rüstungspolitik, die, abgesehen davon, daß sie dem Land eine zu schwere Last auferlegte, nur dann einen Sinn ergab, wenn man unterstellte, daß sie in der Tat auf einen Krieg gegen Frankreich zugeschnitten war. Auf einer Konferenz, die maritime Abrüstung oder doch Rüstungsbegrenzung der fünf Seemächte USA, Großbritannien, Japan, Frankreich und Italien debattieren und beschließen sollte - sie begann am 21. Januar 1930 und zog sich monatelang hin -, steuerte die italienische Delegation einen Kurs, der jedermann klar vor Augen führte, daß Italien im Hinblick auf seine imperialistischen und speziell gegen Frankreich gerichteten Ambitionen gar nicht daran dachte, auch nur auf eines seiner existierenden oder geplanten Kriegsschiffe zu verzichten. Die Londoner Flottenkonferenz endete denn auch mit einem Abkommen, dessen wichtigste Teile lediglich USA, Großbritannien und Japan banden. Italien und damit notgedrungen auch Frankreich hatten sich jeder neuen Beschränkung ihrer Seerüstung verweigert.

In Frankreich blickte man mit wachsender Besorgnis auf Rom. Noch nicht mit Angst. Dazu war Italien denn doch zu schwach, waren seine Ressourcen allzu knapp. Was aber, wenn eine italienisch-deutsche Verbindung zustande kam, die den Angriff auf den Status quo bezweckte? Daß Mussolini die Verständigung mit Berlin suchen werde, stand für die französischen Politiker und Diplomaten außer Zweifel. Am 8. April 1930 prophezeite Briand solche italienischen Bemühungen in einer Unterhaltung mit dem deutschen Botschafter in Paris ${ }^{30}$, und als er den Botschafter einen Monat später fragte, ob Deutschland wohl bald einen italienischen „Bündnisantrag" erhalten werde, war das nur halb scherzhaft gemeint ${ }^{31}$. In solcher Situation mußte danach getrachtet werden, Deutschland vom Eingehen auf italienische Avancen abzuhalten, wenn möglich sogar auf die Seite Frankreichs zu ziehen, und dieses Ziel sahen nicht nur viele professionelle Politiker, sondern sah auch ein stetig wachsender Teil der Bevölkerung. Der deut-

31 Hocsch an AA, 11. 5. 1930; PA, R 70502. 
sche Botschafter in Paris sprach vom „Anschwellen“ der Stimmung für die französisch-deutsche Annäherung 32 .

Es konnte das französische Kabinett und weitere führende Pariser Politiker in ihrem Annäherungswillen nur bestärken, daß sie es mit Repräsentanten deutscher Politik zu tun hatten, die ihr Vertrauen besaßen oder erwarben. Der damalige Leiter des Auswärtigen Amts, Staatssekretär Carl v. Schubert, Neffe des kaiserlichen Staatssekretärs Richard v. Kühlmann und durch das Erbe seiner Mutter, einer geborenen v. Stumm, an der Saarindustrie beteiligt, war ein so überzeugter Anhänger der Annäherung an Frankreich, daß er zum kongenialen Mitarbeiter des Außenministers wurde, ja in den ersten zwei oder drei Jahren die in Stresemanns Politik steckenden echten Verständigungselemente deutlicher sah und bewußter vertrat als dieser selbst $^{33}$. Beide, der Minister und sein Staatssekretär, durften sich außerdem auf die loyale Mitarbeit hervorragender Diplomaten stützen. Zwar hat der Vortragende Legationsrat Ernst Freiherr v. Weizsäcker, der zwölf Jahre später selbst die Leitung des Auswärtigen Amtes übernehmen sollte, am 9. Januar 1926 in einem Brief an seine Eltern räsoniert, die deutsche Diplomatie sei „heruntergekommen“. Aber auch ein solch strenger Kritiker mußte sogleich einräumen, daß es Ausnahmen gebe: „Gut bedient sind wir z.Zt. in Paris..."34

Leopold v. Hoesch, dem sächsischen Zweig einer rheinischen Industriellenfamilie entstammend und finanziell unabhängig, war schon im Januar 1921 als Botschaftsrat nach Paris gekommen und Anfang 1923, nachdem die Ruhrbesetzung zur Abberufung des Botschafters geführt hatte, Geschäftsträger geworden. Er bewährte sich und gewann bei seinen französischen Gesprächs- und Verhandlungspartnern soviel Vertrauen, daß ausgerechnet Ministerpräsident Raymond Poincaré, der deutscher Politik und deutschen Politikern zutiefst mißtraute, der Reichsregierung einen Wink gab, Hoesch zum Botschafter zu ernennen - was dann auch geschah. Thomas Mann, ein scharfer Beobachter seiner Mitmenschen, lernte bei seinem ersten Besuch in Paris nach dem Kriege Hoesch im Januar 1926 kennen und schrieb danach, die Charakterisierung des Botschafters, die einem französischen Journalisten eingefallen war - er hatte den „jeune ambassadeur" als einen Mann mit der "élegance précise d'un capitaine de cavalerie“ bezeichnet - sei ganz falsch: „Die Umgangsformen unseres Geschäftsträgers [sic] entbehren jeder überflüssigen Schärfe und törichten Korrektheit; sie sind zivilisiert und gewinnend, und seine Sprechweise ... ist sanft und gescheit. Bei der Berührung mit ihm versteht man sehr bald die ungewöhnliche Raschheit seines Aufstiegs als Diplomat." Von einer langen Unterredung mit Paul Painlevé,

32 Hoesch an AA, 25. 7. 1930; PA, R 70024.

33 Hierzu Krüger, Die Außenpolitik von Weimar, S. 211, $270 \mathrm{ff}$.

34 Weizsäcker-Papiere, S. 374. 
damals Kriegsminister, gekommen, habe der Botschafter geseufzt: „Die Militärs, die Militärs! Die Sicherheit Frankreichs. Und schließlich hängt man an der ,Armée du Rhin' als Institution, das ist eine Sache, wohltuend zu sagen, glorios. Wir müssen Geduld üben und uns mittlerweile ... die stolze Machtvollkommenheit unserer Zivilregierung vorstellen im Falle, daß Ludendorff gesiegt hätte." 35 Seine Liebenswürdigkeit und sein Verhandlungsgeschick verband er mit außerordentlichem Fleiß, der ihn zu einem genauen und verständnisvollen Kenner der französischen Verhältnisse machte. In seinen Berichten an die Berliner Zentrale vermochte er die innenpolitischen Ursachen aller Züge, Manöver und Reaktionen französischer Außenpolitik präzise zu analysieren und zu erklären; die Ratschläge, die er den Leitern der deutschen Außenpolitik gab, waren stets richtig. Ein geradezu leidenschaftlicher Verfechter nicht nur deutsch-französischer Annäherung, sondern dauerhafter deutsch-französischer Verständigung, war er jedoch sehr wohl Patriot, der deutsche Interessen nicht für eine Sekunde aus den Augen verlor, allerdings realistisch definierte deutsche Interessen. So wurde er, weit über die normale Rolle eines Botschafters hinaus, acht Jahre lang zu einem der wichtigsten Mittler zwischen Berlin und Paris, davon sechs Jahre lang vor allem zwischen Stresemann und Briand ${ }^{36}$.

Der deutsche Botschafter in Rom, Konstantin Freiherr v. Neurath, konnte keineswegs als Anhänger deutsch-französischer Annäherung oder gar Verständigung gelten. Ein Denken in solchen Kategorien lag ihm völlig fern. Sein Kollege Friedrich Wilhelm v. Prittwitz und Gaffron, der von Ende 1927 bis zum 6. März 1933 in Washington als Botschafter amtierte, nannte ihn einen „Deutschnationalen und Stahlhelmer"37. Das war das harte Urteil eines Mannes, der wohl als einziger Angehöriger des deutschen Diplomatischen Dienstes den liberaldemokratischen Parlamentarismus der Republik von Weimar vorbehaltlos bejahte und dem denn auch als einzigem deutschen Diplomaten die Machtübernahme der Nationalsozialisten Anlaß genug war, den Abschied zu nehmen. Aber Neurath zählte in der Tat zu den Anhängern deutschen Großmachtstrebens, nach Versailles also zunächst deutscher Revisionspolitik. Gleichwohl war es verständlich, daß er 1919 mit ausdrücklicher Billigung des Reichspräsidenten Ebert in den Diplomatischen Dienst, den er 1917 quittiert hatte, zurückgeholt worden war ${ }^{38}$. Der Sproß eines alten württembergischen Adelsgeschlechts bewies nämlich Nüchternheit und Klugheit; sein Urteil und sein Verhalten orientierte er mithin stets an den gegebenen Realitäten. Es wäre sicherlich verfehlt, ihn einen Vernunftrepublikaner zu nennen, ihn als einen Diplomaten zu verstehen, der sich aus rationalen Gründen auf lange Jahre einer Stresemannschen

35 Mann, Pariser Rechenschaft, S. 279; die Niederschrift stammt aus dem Januar 1926.

36 Verschau, Leopold v. Hoesch, in: Neue Deutsche Biographie, Bd. 9, S. $367 \mathrm{f}$.

37 Prittwitz, Ein Diplomatenleben, S. 145.

38 Heineman, Hitler's first foreign minister, S. 19. 
Außenpolitik eingerichtet hätte. Doch betrachtete er die Republik von Weimar als die im Augenblick einzige Form der Staatlichkeit, die für die deutsche Nation möglich war, und angesichts der militärischen Schwäche des Reiches den Kurs Stresemanns als unvermeidlich. So vermochte er - bis zu einer Änderung der Verhältnisse - der Republik und der Politik von Locarno loyal zu dienen. Da er außerdem, bei allem Respekt vor Mussolini, wenig Sympathien für den Faschismus und das faschistische System hatte, riet er bei italienischen Avancen zu Zurückhaltung ${ }^{39}$. In Paris ist das nicht unbemerkt geblieben.

Doch konnte sich niemand in Paris und London, in Warschau, Prag, Bukarest und Belgrad verhehlen, daß es noch immer genügend Gründe zur Sorge gab. Zwar wußte man nicht, daß etwa am 24. Juni 1925 der Chef der Heeresleitung, General Hans v. Seeckt, in einer Kabinettssitzung Stresemann und Reichskanzler Hans Luther scharf angegriffen und sozusagen im Namen der Armee erklärt hatte, Deutschland dürfe unter keinen Umständen auf Elsaß-Lothringen verzichten. Wenn jemand sage, hatte er hinzugefügt, im Moment sei doch an die Wiedergewinnung Elsaß-Lothringens gar nicht zu denken, so sage er, Seeckt, man müsse unaufhörlich daran denken; im übrigen könne eine Revision der Grenzen natürlich nur mit Waffengewalt durchgesetzt werden ${ }^{40}$. Auch war sicherlich nicht nach außen gedrungen, daß dem General nicht allein von den deutschnationalen Ministern, sondern selbst von jenen Kabinettsmitgliedern zugestimmt worden war, die dem Zentrum angehörten. Daß aber Stresemann die nach Locarno und zum Eintritt in den Völkerbund führende Politik nur gegen härteste innenpolitische Widerstände hatte durchsetzen können, war naturgemäß nicht zu übersehen gewesen, und jedermann mußte sich eingestehen, daß bei der Beantwortung der Frage, ob der Reichsaußenminister die Mehrheit seiner Kritiker und Gegner inzwischen bekehrt habe, große Skepsis am Platze sei. Die Skepsis schien um so angezeigter, als keineswegs verborgen geblieben war, daß Stresemann seine Politik intern, halböffentlich - in Gremien seiner Partei, der DVP - und gelegentlich auch öffentlich in der Sprache des deutschen Nationalismus und Revisionismus erläutert und sie - was anfänglich ja auch seine eigene Meinung gewesen war - als revisionspolitische Taktik charakterisiert und verkauft hatte: Beruhigung und Frieden - oder doch Waffenstillstand - im Westen, um desto energischer und erfolgreicher Revisionspolitik im Osten, gegen Polen, machen zu können.

Dazu paßte es nur allzu gut, daß Stresemann herkulische Anstrengungen unternommen hatte, um zu verhindern, daß die spezielle und vornehmlich gegen Polen gerichtete Beziehung Deutschlands zur Sowjetunion durch die

39 Vgl. zum Beispiel Bericht Neurath, 19. 5. 1930; PA, R 70024.

40 Meier-Welcker, Seeckt, S. 475. 
Locarno-Politik beschädigt wurde ${ }^{41}$. In dieser Hinsicht war seine Haltung kompromißlos, und die Westmächte - wie ihre ost- und südosteuropäischen Klientelstaaten - hatten sich schließlich damit abfinden müssen, daß das Deutsche Reich erstens ein „Ost-Locarno“, das hieß die Anerkennung auch der deutschen Ostgrenze, verweigerte und zweitens weiterhin die revisionspolitische Karte der deutsch-sowjetischen Verbindung im Spiele hielt: Am 24. April 1926 schloß das Reich demonstrativ mit der Sowjetunion einen Freundschaftsvertrag, der das in Rapallo begründete Verhältnis noch festigte, den sogenannten „Berliner Vertrag“, und am Ende mußten es die Westmächte sogar hinnehmen, daß Deutschland beim Eintritt in den Völkerbund bekundete, sich an nach Artikel 16 der Satzung verhängten Sanktionen der Institution dann nicht $\mathrm{zu}$ beteiligen, wenn sie sich gegen die Sowjetunion richteten.

Es war ein Ausdruck solchermaßen genährter Besorgnis, daß französische Politiker trotz Locarno und trotz des deutschen Eintritts in den Völkerbund fortwährend nach weiteren Stärkungsmitteln zur Kräftigung des Status quo fahndeten. Wenn Briand im Sommer 1927, auf eine amerikanische Initiative reagierend, den USA einen Vertrag vorschlug, in dem sich Frankreich und die Vereinigten Staaten zusichern sollten, nie Krieg gegeneinander zu führen, leitete ihn nicht Optimismus, sondern der Zweifel an der Funktionstüchtigkeit des Völkerbunds und des Systems der kollektiven Sicherheit; die USA sollten wieder zu einem stärkeren politischen Engagement in Europa gebracht werden. Der amerikanische Außenminister Frank B. Kellogg antwortete im Dezember, der Vertrag sei nützlicher, wenn er aus einem bilateralen in ein multilaterales Unternehmen umgewandelt werde, und tatsächlich unterzeichneten am 27. August 1928 die Vertreter von fünfzehn Staaten in Paris ein Abkommen, das zum Verzicht auf Krieg als Mittel nationaler Politik verpflichtete; bis 1933 traten dem Briand-Kellogg-Pakt nicht weniger als fünfundsechzig Nationen bei ${ }^{42}$.

Briand hätte zufrieden sein können, war es aber nicht, da der Vertrag keine Sanktionsklauseln und keine neuen Abrüstungsversprechen enthielt, also rein deklaratorischen Charakter besaß. So setzte er die Suche nach zusätzlichen Sicherheitsgarantien fort und regte im Herbst 1929 an, erste organisatorische Stützen eines europäischen Staatenbundes zu schaffen: eine regelmäßig tagende Konferenz der europäischen Staaten, einen permanenten politischen Ausschuß als Exekutivorgan und ein Sekretariat. Am 17. Mai 1930 hat er seine Gedanken, zusammengefaßt in einem Memorandum über die „Organisation eines Systems eines europäischen Staatenbun- 
des“, den sechsundzwanzig europäischen Mitgliedstaaten des Völkerbunds offiziell übermittelt ${ }^{43}$.

Beruhigend wirkte indes der Eindruck, daß Stresemann selbst in den Jahren nach 1926 vom revisionspolitischen Taktiker zum aufrichtigen Verständigungspolitiker geworden war. Er tummelte sich im internationalen Parlamentarismus, wie er im Genfer Völkerbund institutionalisiert worden war, offensichtlich mit dem gleichen Geschick und mit der gleichen Lust wie im heimischen Parteiengetriebe und im Berliner Reichstag. Hatte er sich nicht doch daran gewöhnt, bei der Lösung der internationalen Probleme Deutschlands den Weg über Genf zu suchen? Und konnte dem nicht doch die Gewöhnung an den Status quo folgen? Dafür sprach immerhin, daß Stresemann und Staatssekretär v. Schubert die Einladung, dem Kellogg-Pakt beizutreten, sofort und mit allen Anzeichen der Zustimmung zu Sinn und Zweck des Abkommens angenommen hatten ${ }^{44}$. Dafür sprach ebenfalls, daß Stresemann die Europapläne Briands enthusiastisch begrüßte, obwohl ihm klar sein mußte, daß es Briand in erster Linie um die Stabilisierung des Status quo ging ${ }^{45}$; mißvergnügt schrieb ein jüngerer deutscher Diplomat, der Reichsaußenminister wolle Briand noch „überbieten“ 46 .

Wahrscheinlich ist der Eindruck, Stresemann habe eine Entwicklung durchgemacht, richtig gewesen: Die Zusammenarbeit mit Frankreich, anfänglich gewiß nur situationsbedingt und revisionspolitisches Manöver, begriff er im Lauf der Jahre offenkundig als dauerhafte Aufgabe deutscher Politik, und zwar nicht allein im Interesse Deutschlands, sondern gleichermaßen im Interesse Europas; dies bedingte aber, daß er den Verzicht auf Elsaß-Lothringen allmählich für nicht mehr rücknehmbar hielt. Außerdem ist nicht zu verkennen, daß die Rückgewinnung der an Polen verlorenen Territorien für ihn 1929 nicht mehr die gleiche Bedeutung besaß wie 1925. Ein endgültiges Urteil ist allerdings nicht möglich, da Gustav Stresemann am 3. Oktober 1929 verstarb. Bis zu seinem Tod war er jedenfalls eine Hoffnung der Anhänger des europäischen Status quo und der Freunde des Friedens geworden, und die Hoffnung, die man auf ihn setzte, verband sich weithin mit der freilich nur zaghaft keimenden Annahme, daß eine Mehrheit der Deutschen den gleichen Gewöhnungsprozeß erlebt hatte wie der Außenminister.

Noch ein Umstand schien eine gewisse Zuversicht zu rechtfertigen. Stresemann hatte in der Reparationsfrage tatsächlich recht behalten. Als das fünfte Jahr des Dawes-Plans und mit ihm eine erhebliche Erhöhung der von Deutschland zu zahlenden Jahresraten näher rückte, mußte wirklich neu

43 Ebenda, S. $523 \mathrm{ff}$.

44 Hierzu Knipping, Das Ende der Locarno-Ära, S. $84 \mathrm{ff}$. Heinemann, Hitler's first foreign minister, S. 19.

45 Ebenda.

46 Weizsäcker-Papiere, S. 392. 
verhandelt werden, und zwar alles in allem doch zum Vorteil des Reiches ${ }^{47}$. Bereits Ende 1927 verlangte Parker Gilbert, der für den Transfer der deutschen Raten zuständige und in Berlin residierende amerikanische Reparationsagent, eine Prüfung des Problems, weil er überzeugt war, Deutschland werde die höheren Annuitäten nicht aufbringen können. Die französische Regierung unterstützte Gilberts Forderung, wenn auch aus einem ganz anderen Grunde. Frankreich war um seiner amerikanischen Schulden willen an einer größeren deutschen Devisenleistung und daher an einer teilweisen Aufhebung des im Dawes-Plan verankerten Transferschutzes interessiert. Die Reichsregierung nützte die Situation jedenfalls sofort und geschickt aus; ihr Ansuchen um eine Modifizierung des Dawes-Plans hatte Erfolg.

Allerdings blieb der Plan, den eine seit Februar 1929 in Paris konferierende und von dem amerikanischen Bankier Owen D. Young geleitete Kommission internationaler Finanzexperten am 7. Juni 1929 vorlegte, in einer Hinsicht hinter den deutschen Wünschen zurück. An den alliierten Kriegsschulden orientiert, wozu noch ein relativ bescheidener Zuschlag zur Behebung von Kriegsschäden kam, sah der Young-Plan zwar in der Tat vorerst geringere Jahresraten vor, doch dann erneut ein Ansteigen der Annuitäten und vor allem eine Laufzeit der Zahlungen bis 1988. Auf der anderen Seite sollte der Apparat, der zur internationalen Kontrolle der deutschen Finanzen und der deutschen Reparationsleistung geschaffen worden war, abgebaut werden, und in einer Zeit, da die Nationen und ihre politischen Repräsentanten souveränitätssüchtig waren, galt schon das als ganz großer Gewinn. Daß man sich finanzpolitisch nun wieder als Herr im eigenen Haus fühlen durfte, wog schwerer als der damit verbundene partielle Wegfall des Transferschutzes, der die deutsche Währung vor all jenen Gefahren bewahrt hatte, die drohen, wenn ein Staat anderen Staaten hohe Summen ohne wirtschaftlichen Grund zahlt.

Die Verhandlungen, die der Vorlage des Plans folgten, sind sowohl von Frankreich wie von Deutschland - wo in diesem Falle der Außenminister ja nicht allein agieren konnte - mit einer die jeweilige Gegenseite und alle übrigen Beteiligten erbitternden Kleinlichkeit geführt worden ${ }^{48}$. Gleichwohl endeten sie erfolgreich. Was Paris anging, so lag das daran, daß Frankreich wieder unter starken angelsächsischen Druck geraten war und die Pariser Regierung den Young-Plan für die französische Öffentlichkeit schließlich doch als großen Triumph eigener Reparationspolitik zu frisieren vermochte. In Berlin hingegen wußten Regierung und seriöse Beobachter - wie das auch Politiker und Finanzleute außerhalb Deutschlands wußten -, daß das künftige Ansteigen der Jahresraten ebenso nur auf dem Papier stand wie die irrsinnig lange Laufzeit der Reparationsverpflichtung. Nicht anders als der

47 Knipping, Das Ende der Locarno-Ära, S. $58 \mathrm{ff} ., 96 \mathrm{ff}$.

48 Ebenda. 
Dawes-Plan galt auch der Young-Plan allgemein lediglich als Provisorium; in einigen Jahren würde er von einem neuen und für Deutschland abermals günstigeren Abkommen abgelöst werden. Daher durfte man die Vorteile, die der Plan für die erste Phase seiner Geltungszeit brachte, ruhig annehmen, ohne daß Sorgen um die Zukunft allzu schwer zu drücken brauchten. Als Stresemann auf einer Haager Konferenz, die vom 6. bis zum 31. August 1929 stattfand, seine Zustimmung zum Young-Plan endlich auch mit dem französischen Versprechen belohnt sah, die beiden letzten Besatzungszonen im Rheinland vorzeitig zu räumen, war es zudem möglich, die innenpolitischen Gegner des Ministers und des Plans in Schach zu halten. Auf einer zweiten Haager Konferenz, die vom 3. bis zum 20. Januar 1930 währte und die Stresemann nicht mehr erlebte, wurde der Plan endgültig angenommen.

In Frankreich, in Großbritannien, in den Vereinigten Staaten, auch in Polen und in den Ländern der Kleinen Entente, glaubten nun viele, daß das Reparationsproblem wenigstens für etliche Jahre aus der Politik verbannt und damit eines der größten Hindernisse auf der Bahn zur europäischen Verständigung für eine wichtige Zeitspanne zur Seite geschoben sei. Wohl war zu sehen gewesen, daß der Young-Plan in Deutschland auf heftigste Gegnerschaft gestoßen war. Die Deutschnationale Volkspartei, der „Stahlhelm“ - eine große Organisation ehemaliger Frontsoldaten -, der Landbund, die Landvolkpartei, die NSDAP und einige andere rechtsgerichtete Verbände hatten schon am 9. Juli 1929 einen Reichsausschuß für ein Volksbegehren gegen den Young-Plan ins Leben gerufen, und dieser Reichsausschuß entwarf ein "Gesetz gegen die Versklavung des deutschen Volkes“, das vorsah, Regierungsmitglieder, die Verpflichtungen wie den Young-Plan unterschreiben, wegen „Landesverrats" vor Gericht zu stellen ${ }^{49}$. Da Alfred Hugenberg, nicht nur Führer der Deutschnationalen, sondern auch $\mathrm{Me}-$ dienzar, zu den Inspiratoren des Volksbegehrens gehörte, kommentierte Harold Nicolson, Botschaftsrat an der Berliner Mission Großbritanniens, später ein Schriftsteller und Unterhausabgeordneter, der sich nach seinem Tode als einer der großen politischen Tagebuchschreiber des Jahrhunderts entpuppte ${ }^{50}$, in einem Bericht an das Foreign Office: „Dieser Gesetzentwurf ist für den nichtdeutschen Geist phantastisch. Als ob Lord Rothermere [Daily Mail, Daily Mirror, London Evening News] sich die Führung der Konservativen Partei gesichert und dann der Wählerschaft einen Vorschlag unterbreitet hätte, der jede Vereinbarung mit Amerika über Flottenabrüstung ablehnt und jeden Minister Seiner Majestät, der eine solche Vereinbarung unterzeichnet, mit einem Strafverfahren bedroht." 51 Jedoch

49 Deutsche Allgemeine Zeitung, Nr. 422, 12. 9. 1929.

50 Nicolson, Diaries and letters.

51 Nicolson an Henderson, 4. 12. 1929; DBFP, Series Ia, Vol. VII, Nr. 109. 
scheiterte das Volksbegehren, für das sich am 22. Dezember 1929 nur 13,8 Prozent der Stimmberechtigten erklärten, und der Reichstag nahm den Young-Plan am 11./12. März 1930 an. So ist es nicht verwunderlich, daß Orme G. Sargent, Leiter der Zentralabteilung im Foreign Office, am 24. Februar 1930 in einem Brief an Sir Eric Phipps, den britischen Gesandten in Wien, meinte, die Bescheidenheit und Zurückhaltung, mit der das Reich auf italienisches und österreichisches Werben reagiere, sei hoffentlich ein Anzeichen dafür, „daß jetzt, da die Reparations- und die Räumungsfrage aus dem Wege sind, Deutschland sich eher auf inneren Aufbau und innere Entwicklung konzentrieren wird als auf auswärtige Probleme wie Korridor und Anschluß"52. Vier Tage später äußerte sich Sir Horace Rumbold, der britische Botschafter in Berlin, im gleichen Sinne ${ }^{53}$.

In dieser entspannteren Atmosphäre vermochte Botschafter v. Hoesch seine Stellung in Paris noch zu festigen, und die deutsch-französische Annäherung schien trotz der Reibereien, die der Annahme des Young-Plans vorhergegangen waren, weiter Fortschritte zu machen. Im Januar 1930 schrieb Lord William Tyrrell, der britische Vertreter in Paris, an Sir Robert Vansittart, Staatssekretär im Foreign Office: „Die Deutschen hier sind im Augenblick mit den Franzosen anscheinend in engstem Einvernehmen, und die Intimität ihrer Beziehungen ist für mich eine fortwährende Überraschung und würde vermutlich die Leute in London höchlichst überraschen. "54 Nach solchem Tribut an Hoeschs diplomatische Leistung konstatierte Lord Tyrrell einige Tage später, auch die Franzosen arbeiteten hart an einem besseren Verhältnis zu Deutschland - "um Italien auszustechen“. Tatsächlich war der Botschafter über die französische Deutschlandpolitik schon nicht mehr rundum glücklich. Französische Politiker, Wirtschaftler, Diplomaten und unter ihrem Einfluß Briand, so sagte er, seien „bereit, Europa mit Deutschland ohne uns zu organisieren" 55 .

52 Sargent an Phipps, 24. 2. 1930; DBFP, Series Ia, Vol. VII, Nr. 248.

53 Rumbold an Henderson, 28. 2. 1930; DBFP, Series Ia, Vol. VII, Nr. 262.

54 Tyrrell an Vansittart, 28. 1. 1930; DBFP, Series Ia, Vol. VII, Nr. 231.

55 Tyrrell an Vansittart, 11. 2. 1930; DBFP, Series Ia, Vol. VII, Nr. 243. 